\title{
Prolyl hydroxyl Binding Protein (PHD) and its Linkage to Changes in MyD88/p65 Pathway in Renal Injury Induced by Nitric Oxide Deficiency and High Salt Diet
}

\author{
Choi C and Oyekan A0* \\ Center for Cardiovascular Diseases, College of Pharmacy and Health Sciences, Texas Southern University, USA
}

Submission: June 26, 2016; Published: July 12, 2017

*Corresponding author: Adebayo Oyekan, Center for Cardiovascular Diseases, College of Pharmacy and Health Sciences, Texas Southern University, Houston, TX 77004, USA, Tel: (713) 313 4258/4341; Fax: (713) 313 4342; Email: Oyekan_AO@TSU.EDU

\begin{abstract}
Oxidative stress and associated inflammation, features of hypertension and kidney disease, involve many mediators. Nrf2, a transcription factor, the primary cellular defense against oxidative stress and MyD88, an adaptor protein has been implicated in inflammation and consequent NFKB activation. Prolyl hydroxyl binding protein (PHD), an oxygen sensor in hypoxia is also intricately linked to inflammation/oxidative stress. This study evaluated the contribution of PHD in association with Nrf2, MyD88 and NFkB to nitric oxide (NO) deficiency-induced hypertensive renal injury. LNNA, inhibitor of NO synthase reduced PHD2 $(\mathrm{P}<0.05)$ but not PHD1 expression and increased blood pressure $(\mathrm{BP}$; $\mathrm{P}<0.05)$, protein excretion ( 3.5 -fold, $\mathrm{P}<0.05$ ) and KIM-1 expression (3.8-fold, $\mathrm{P}<0.05)$. DMOG did not affect LNNA-induced reduction in PHD2 expression and the elevated BP but blunted the proteinuria and KIM-1 expression.

DMOG also blunted decreased Nrf2 expression, increased nuclear expression of p65 $(\mathrm{P}<0.05)$ and MyD88 $(\mathrm{P}<0.05)$, increased serum TNFa and IL-1 $\beta(P<0.05)$ production and xanthine-induced renal production of $\mathrm{H}_{2} \mathrm{O}_{2}(\mathrm{P}<0.05)$ LNNA-treated animals. These data suggest a protective role for PHD2 that is linked to changes in MyD88/p65 expression and cytokine production in the renal injury and inflammation induced by NO deficiency and high salt diet.
\end{abstract}

Keywords: Prolyl-4-hydroxylase domain (PHD); High salt diet; Hypertension; KIM-1; Nitric oxide; Nrf2; Myd88; p65

Abbreviations: SOD: Super Oxide Dismutase; HO-1: Heme Oxygenase-1; ROS: Reactive oxygen species , GST: Glutathione S-Transferase; GPx: Glutathione Peroxidase; PHDs: Prolyl Hydroxyl Binding Proteins; HIF: Hypoxia-Inducible Factor

\section{Introduction}

Chronic inflammation is an important path physiological condition impacting various diseases including but not limited to hypertension, kidney disease, atherosclerosis, diabetes, cancer, etc. Reduced nitric oxide (NO) bioavailability, a feature of these conditions, plays a causal role in endothelial cell dysfunction and inflammation. NO is a key regulatory molecule of paramount importance for endothelial function including its anti-inflammatory and other protective cellular effects. Thus, reduced NO bioavailability is associated with various diseases that involve activation of NF-kB $[1,2]$ and subsequent gene transcription of cytokines (TNF $\alpha$, IL-1, IL-6) that mediate inflammatory responses [3].

Reactive oxygen species (ROS) constitute one of the many mediators of inflammation so also are prolyl-4-dioxygenases also known as prolyl hydroxyl binding proteins (PHDs). ROS production within the cell is finely modulated by enzymatic and no enzymatic antioxidant defenses. Nuclear factor (erythroidderived 2)-like 2 ( $\mathrm{Nrf2}$ ), the redox-sensitive transcription factor, is an important antioxidant that serves as a master regulator of antioxidant system through increased expression of several antioxidant enzymes. It plays a critical role in basal activity and coordinated induction of genes encoding numerous antioxidant and phase II detoxifying enzymes and related proteins; namely, such as superoxide dismutase (SOD), catalase (CAT), UDPglucuronosyltransferase, NAD(P)H:quinone oxidoreductase-1 (NOQ1), heme oxygenase-1 (HO-1), glutamate cysteine ligase, glutathione S-transferase (GST), glutathione peroxidase (GPx), and thioredoxin, among others [4]. 
Through these proteins, Nrf2 regulates cellular antioxidant and anti-inflammatory machinery thereby serving as the primary cellular defense against the cytotoxic effects of oxidative stress $[4,5]$ and when impaired, there is severe oxidative stress and inflammation and progression of tissue damage in kidney injury [6]. On the other hand, prolyl hydroxyl binding proteins (PHDs) are a group of iron, 2-oxoglutarate, and oxygendependent dioxygenases are enzymatic gatekeepers serving as oxygen sensors of the body's adaptive response to hypoxia. Of therapeutic interest is that inhibitors of the PHDs, which permit the activation of hypoxic adaptation under conditions of normoxia, are protective in various models of cardiovascular diseases [7-9] and inflammation [10]. In studies that examined interactions of NO and PHD, acute and high doses of NO inhibited PHD expression/activity [11] while low doses or prolonged exposure to NO led to induction of PHD activity $[12,13]$.

Although pathways involved in renal oxidative stress and inflammation in renal disease are well known $[6,14,15]$, the role of PHD as a signaling event in NO withdrawal-induced renal oxidative stress and inflammation has received little attention. Considering the established distinct roles of NO/oxidant species on one hand $[16,17]$ and PHD on the other in the path physiology of hypertension, the current study evaluated the relationship between PHD2 and Nrf2/oxidative stress on hypertensive kidney injury and inflammation following NO withdrawal. The overall interaction with MYD88/NFkB pathway was also evaluated. Our data demonstrated a selective down-regulation of PHD2 in tandem with Nrf2 but increased ROS generation and up regulation of NFKB and MyD88.

\section{Materials and Methods}

Unless specified otherwise in the text, all chemicals were obtained from Sigma-Aldrich (St Louis, Missouri, USA) and are of the highest analytical grade. Dimethyloxallyl glycine (DMOG) was purchased from Cayman Chemical Company (Ann Arbor,

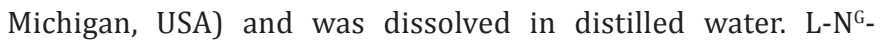
Nitroarginine (L-NNA) was dissolved in $0.1 \mathrm{~mol} / \mathrm{l} \mathrm{NaHCO}_{3}$ in a stock concentration of $100 \mathrm{mg} / \mathrm{ml}$ and subsequent dilution was made in tap water. Xanthine was dissolved in $0.1 \mathrm{~mol} / \mathrm{l} \mathrm{NaHCO}_{3}$ in a stock concentration of $100 \mathrm{mg} / \mathrm{ml}$ and subsequent dilution was made in distilled water. This study was approved by the Animal Care Committee of the Texas Southern University and conforms to the institutional guidelines on animal care and use.

This study was carried out in male rats (334-398 g; mean, 363+14 g, Sprague-Dawley; Harlan Sprague-Dawley, Houston, Texas, USA) treated with L-NNA to inhibit nitric oxide synthesis or DMOG, a cell-permeable, competitive inhibitor of PHD proteins leading to stabilization of hypoxia-inducible factor (HIF). In these experiments, rats were randomly divided into four groups, viz, animals receiving normal salt diet and tap water orally ad libitum (Control, $\mathrm{n}=5-7$ ), animals placed on L-NNA
(250 $\mathrm{mg} / \mathrm{l}$ in drinking water ad libitum for 14 days) and high salt $\operatorname{diet}(4 \% \mathrm{NaCl})$ and treated with vehicle [distilled water, $1 \mathrm{ml} /$ $\mathrm{kg}$, intraperitoneally (i.p.) daily; $\mathrm{n}=7-9$ ], and animals placed on L-NNA, high salt diet, and DMOG (15 mg/kg i.p. daily; L-NNA + DMOG, $\mathrm{n}=6-8$ ) or animals treated with DMOG alone (DMOG, 15 $\mathrm{mg} / \mathrm{kg}$ i.p. daily; $\mathrm{n}=5-6$ ). This dose of DMOG, based on literature and our previous studies that showed significant inhibition of PHD expression [18]. Animals were placed in metabolic cages for 24-h urine collection for biochemical analyses of sodium (UNaV) and protein (UProtV).

Urine collection was done on days $0,4,7$ and 14.2-3 days before the end of the study, all animals were instrumented under sodium pentobarbital anesthesia (50 mg/kg; i.p.) for placement of indwelling catheters in the left carotid artery. The catheters were exteriorized through the nape of the neck and the ends capped with a three-way tap for subsequent blood collection and blood pressure determination in the conscious state. At the end of the study period, blood pressure determination was made in all animals after which they underwent sodium pentobarbital anesthesia (50 mg/kg; i.p.) for blood collection and eventual serum preparation. Kidney tissues were also harvested and snap frozen in liquid nitrogen for immunoblotting experiments. In a subset of animals, renal generation of reactive oxygen species (ROS) was evaluated. This was accomplished by determining $\mathrm{H}_{2} \mathrm{O}_{2}$ production (Apollo System (model 400, WPI, Sarasota, Florida) in sodium pentobarbital-anesthesized (50 mg/kg; i.p.) animals in response to intravenous administration of xanthine $(3,5$, and $10 \mathrm{mg} / \mathrm{kg}$ ) using size 23G butterfly needle (Abott Laboratories, Franklin Lakes, NJ) placed in the tail vein.

\section{Biochemical analyses}

Urinary protein was determined using a colorimetric kit from Sigma-Aldrich (St Louis, Missouri, USA).

\section{Evaluation of cytokine release}

The generation of TNF $\alpha$ and IL-1 $\beta$ in the serum was determined using Signosis's Oxidative Stress ELISA Strip Profiling Assay (Signosis Inc, Santa Clara, CA, USA).

\section{Determination of ROS production}

$\mathrm{H}_{2} \mathrm{O}_{2}$ was determined in a set of animals ( $n=5$ per group) that were randomly allocated to treatment with vehicle and normal salt diet (Control), LNNA with or without DMOG ( $\mathrm{n}=5$ per group). $\mathrm{H}_{2} \mathrm{O}_{2}$ generated was measured with an isolated electrode-based free radical detection system (Apollo 4000, World Precision Instruments) using an electrochemical (amperometric) detection principle using an $\mathrm{H}_{2} \mathrm{O}_{2}$ electrode (sensor) (HPO Sensor; ISOHPO-100, World Precision Instruments, Sarasota, Florida). The oxidation of $\mathrm{H}_{2} \mathrm{O}_{2}$ at the electrode (sensor) surface produces a small current ( $\mathrm{pA}$ ) that is coupled to data acquisition module driven by a Digital Signal Processor for real time measurement of $\mathrm{H}_{2} \mathrm{O}_{2} \cdot \mathrm{H}_{2} \mathrm{O}_{2}$ electrode was inserted to a depth of no more than 
$1 \mathrm{~mm}$ (cortex) and after a stable baseline was reached (usually within 10 minutes of placement), current was measured at 15 second intervals for 5 minutes. The current generated in response to intravenously administered xanthine was converted to $\mathrm{H}_{2} \mathrm{O}_{2}$ concentration using a standard curve of standard $\mathrm{H}_{2} \mathrm{O}_{2}(1$, 2,4 , and $8 \mu \mathrm{M}$ ) in PBS. Base current was extracted to determine the actual amount of $\mathrm{H}_{2} \mathrm{O}_{2}$ generated.

\section{Immunoblotting for protein expression}

Kidney tissues were homogenized with SDS sample buffer containing protease inhibitors for cellular extraction. Protein expression of PHD-1 and PHD-2, KIM-1, or MyD88 was evaluated in whole kidneys while p65 or Nrf2 expression was evaluated in nuclear fractions. Pellets were vortexes for $15 \mathrm{sec} 4$ times at 10 min intervals with nuclear extraction buffer and then centrifuged for $30 \mathrm{~min}$ at $14,000 \mathrm{rpm}$ at $4^{\circ} \mathrm{C}$. Protein concentration was measured with the BCA protein assay kit (Pierce Biotechnology Rockford IL, USA). $50 \mu$ g of protein was then loaded onto $10 \%$ polyacrylamide gels for SDS-PAGE. Separated proteins were transferred to PVDF membranes and probed with appropriate antibodies - PHD1 and PHD2, MyD88, Nrf2, p65, $\beta$-actin, beclin 1 (Abcam, Cambridge, MA, USA) and KIM-1 (R\&D Systems, Inc., Minneapolis, MN, USA). Primary antibodies were diluted 1:1000 and incubated overnight at $4^{\circ} \mathrm{C}$. After washing, the blots were incubated with appropriate horseradish peroxidase conjugated secondary antibodies. Immunodetection was performed using luminol reagent (Santa Cruz Biotechnology, Santa Cruz CA, USA). $\beta$ actin or GAPDH was used as internal control. Protein band intensities were measured using Molecular Imager FX and Quantity One software (Bio-Rad, Hercules, CA, USA).

\section{Statistical analysis}

Values were presented as mean + SEM. Means were compared between groups and between treatments for significant difference using Analysis of Variance. In all cases, $\mathrm{P}<0.05$ was considered as statistically significant.

\section{Results}

Effects of inhibition of nitric oxide production on expression of prolyl hydroxylase domain-containing protein on the expression of PHD following nitric oxide synthase inhibition and high salt diet

Figure 1 illustrates that there was no change in the expression of PHD1 in the whole kidney of $(n=7)$ rats treated with L-NNA (250 mg/L in drinking water for 14 days) and high salt diet neither did the addition of DMOG $(15 \mathrm{mg} / \mathrm{kg}$, i.p., LNNA/ DMOG, $n=6$ ) affect basal expression of PHD1. By contrast, PHD2 expression was reduced in animals placed on L-NNA $(29+3 \%$; $\mathrm{P}<$ 0.05). DMOG did not cause further reduction of PHD2 expression in animals treated with L-NNA (LNNA/DMOG). Similarly, DMOG alone $(n=5)$ did not affect basal expression of PHD2.

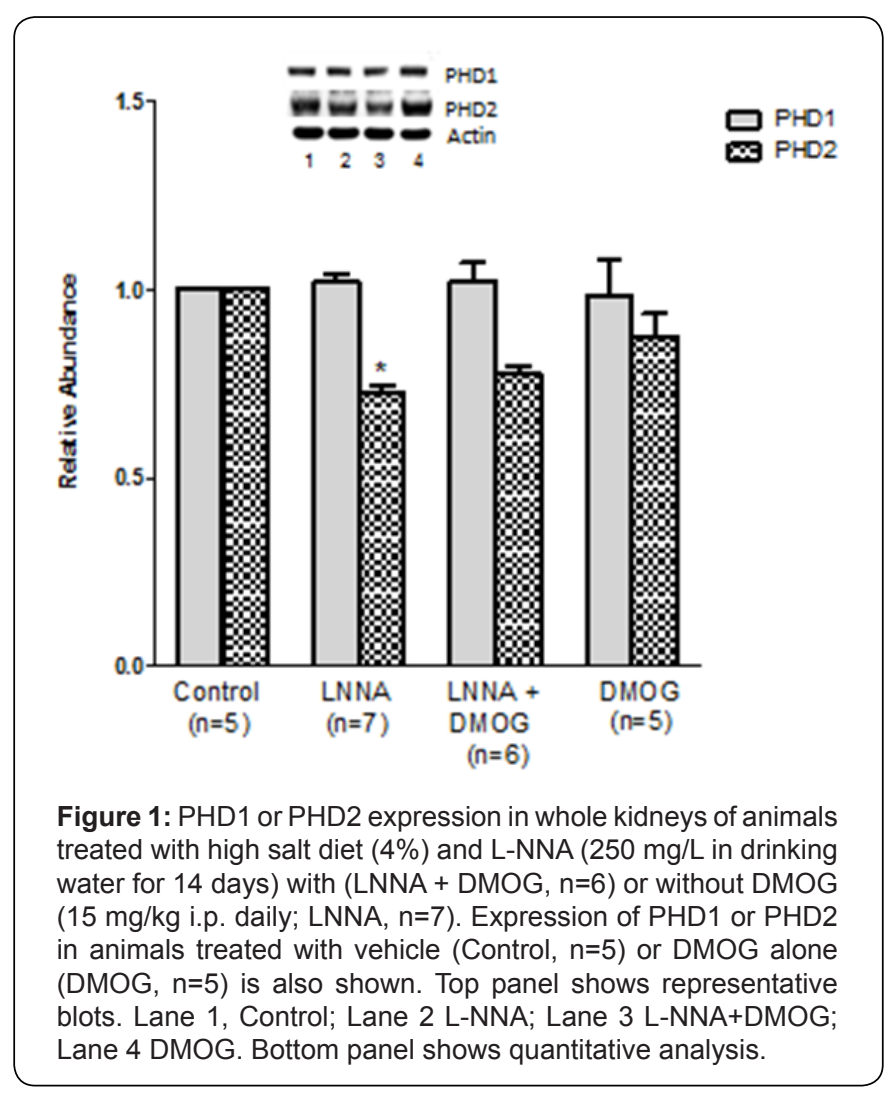

${ }^{*} \mathrm{P}<0.05$ (L-NNA versus Control).

Effects of inhibition of prolyl hydroxylase domaincontaining protein on blood pressure and sodium excretion in rats following nitric oxide withdrawal and high salt diet

Figure 2a illustrates that mean arterial blood pressure increased by $31+5 \%(\mathrm{P}<0.05)$ on Day 14 in rats $(\mathrm{n}=9)$ placed on L-NNA (250 mg/L in drinking water for 14 days). DMOG (15 $\mathrm{mg} / \mathrm{kg}$, i.p.) did not affect elevated blood pressure in L-NNA/ high salt-fed rats (LNNA/DMOG, n=8). On its own, DMOG also did not affect blood pressure as blood pressure in DMOG-treated animals (DMOG, $\mathrm{n}=6$ ) was not different from that of control rats.

Figure $2 \mathrm{~b}$ illustrates that compared to control rats, sodium excretion increased $(3.2$-fold; $\mathrm{P}<0.05)$ over the course of the study in animals placed on L-NNA and high salt diet. The increase peaked by Day 7 and remained unchanged by Day 14 . DMOG had no effect on sodium excretion in L-NNA/high salt-fed rats (L-NNA+DMOG, $n=8$ ) as there was no difference in sodium excretion in these animals when compared to those that received vehicle (L-NNA; $\mathrm{P}>0.05$ ). Sodium excretion in animals treated with DMOG alone (DMOG, $n=6$ ) was also not different from those of control animals. Moreover, there was no marked change in sodium excretion between animals treated with vehicle (Control, $n=7)$ or DMOG $(n=6)$ on each day of the study. 
(a)

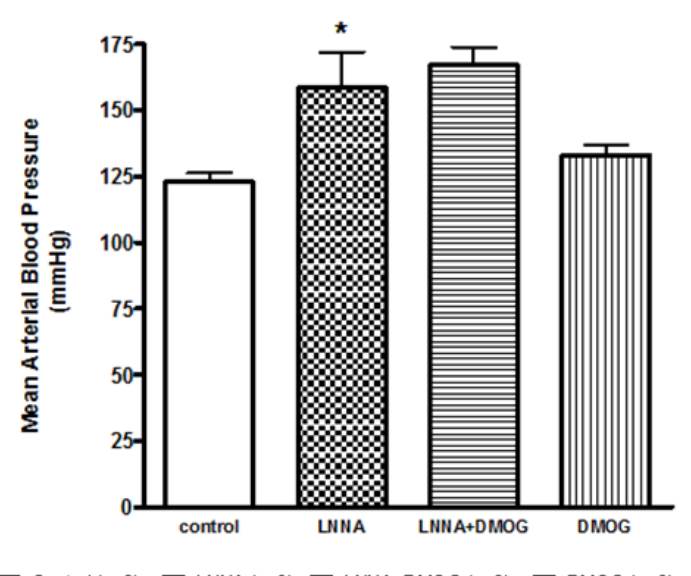

$\square$ Control (n=6) 冈 LNNA (n=9) 曰 (b)

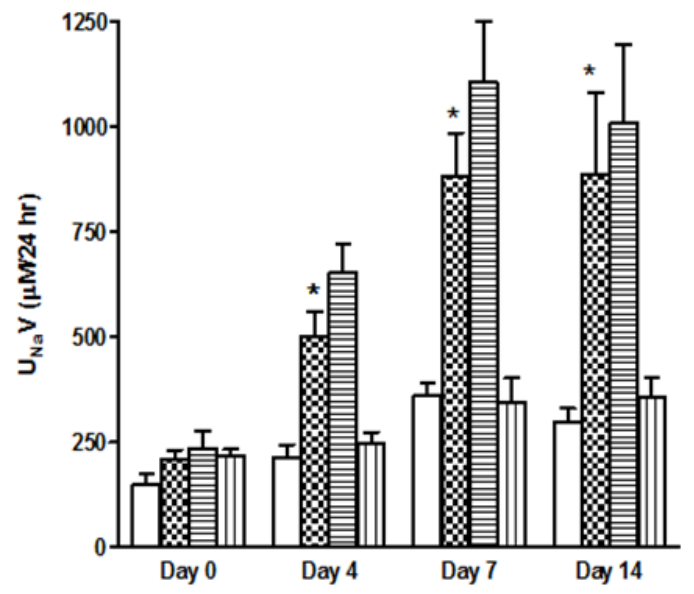

Figure 2: Mean arterial blood pressure (a) or protein excretion in the urine (b) of animals treated with high salt diet $(4 \%)$ and L-NNA ( $250 \mathrm{mg} / \mathrm{L}$ in drinking water for 14 days) with (LNNA + DMOG, $\mathrm{n}=8$ ) or without DMOG (15 mg/kg i.p. daily; LNNA, $\mathrm{n}=9$ ). Expression of PHD1 or PHD2 in animals treated with vehicle (Control, $n=6$ ) or DMOG alone (DMOG, $n=6$ ) is also shown. Top panel shows representative blots. Bottom panel shows quantitative analysis.

${ }^{*} \mathrm{P}<0.05$ (L-NNA versus Control)

Effects of inhibition of prolyl hydroxylase domaincontaining protein on proteinuria in rats following nitric oxide synthase inhibition and high salt diet

Figure 3 illustrates that there was no change in protein excretion in control rats throughout the study period. However, compared to Day 0, there was a steady increase in proteinuria reaching 1.6-fold increase $(\mathrm{P}<0.05)$ on Day 7 and 3.3 -fold increase $(\mathrm{P}<0.05)$ on Day 14 in $\mathrm{L}-\mathrm{NNA} /$ high salt-fed $(\mathrm{n}=9)$ rats that received vehicle (L-NNA). The increase was blunted in rats placed on DMOG (L-NNA + DMOG; P<0.05) on Day 14 when DMOG blunted the proteinuria by $43+6 \%(\mathrm{P}<0.05)$. KIM1, a biomarker of kidney tubular injury, increased (2.6 fold, $\mathrm{P}<0.05)$ in $\mathrm{L}-\mathrm{NNA} / \mathrm{high}$ salt-fed $(\mathrm{n}=7)$ rats that received vehicle (a)
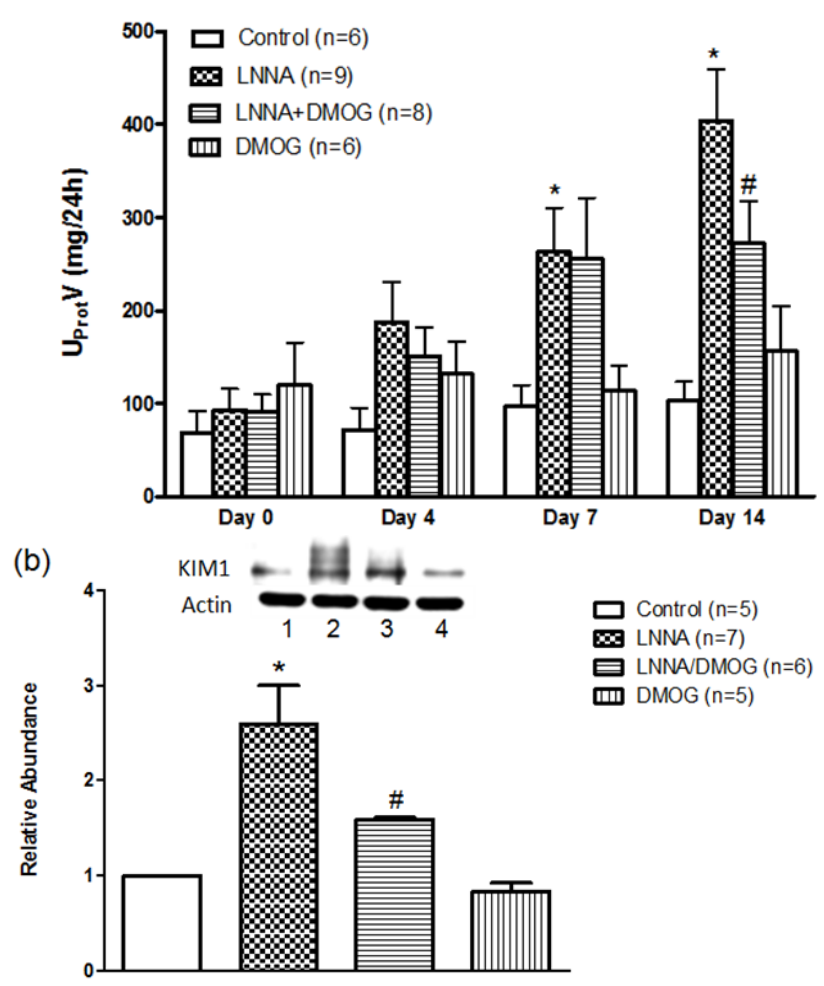

Figure 3: Protein excretion in urine (a) and expression of KIM-1 (b) in renal tissue (whole kidneys) of animals treated with high salt diet $(4 \%)$ and L-NNA (250 mg/L in drinking water for 14 days) with (LNNA + DMOG) or without DMOG (15 mg/kg i.p. daily; LNNA). Data in animals treated with vehicle (Control) or DMOG alone (DMOG) is also shown. Representative blots and corresponding quantitative analysis for $\mathrm{KIM}-1$ expression are shown. Lane 1, Control; Lane 2 L-NNA; Lane 3 L-NNA+DMOG; Lane 4 DMOG. The number of animals in each group is as annotated.

Effects of inhibition of prolyl hydroxylase domaincontaining protein on generation of $\mathrm{H} 202$ and $\mathrm{Nrf} 2$ expression in rats following nitric oxide synthase inhibition and high salt diet

Reduced NO bioavailability is associated with increased generation of reactive oxygen species $[16,17]$. Basal generation of $\mathrm{H}_{2} \mathrm{O}_{2}$ in vehicle-treated $(\mathrm{n}=5)$ rats was $12+1.2 \mu \mathrm{M}$, a value not significantly different from that of L-NNA/high salt-fed $(n=5)$ rats $(14.7+1.7 \mu \mathrm{M})$. Figure 4 illustrates that there was a dosedependent increase in the generation of $\mathrm{H}_{2} \mathrm{O}_{2}$ in response to intravenously administered xanthine $(3,5$, and $10 \mathrm{mg} / \mathrm{kg})$. This increase, manifested both in peak response and area under the curve, was greater in L-NNA/high salt-fed rats $(\mathrm{P}<0.05, \mathrm{n}=5)$ compared with control $(n=5)$ animals. The increase in $\mathrm{H}_{2} \mathrm{O}_{2}$ generation (area under the curve) was most marked at the lowest dose of xanthine (1.42-fold; $\mathrm{P}<0.05)$. The corresponding increases at the 5 and $10 \mathrm{mg} / \mathrm{kg}$ doses of xanthine were $63+5 \%$ $(\mathrm{P}<0.05)$ and $29+4 \%$ increase $(\mathrm{P}<0.05)$, respectively. DMOG $(n=5)$ blunted the increases in $\mathrm{H}_{2} \mathrm{O}_{2}$ generation $(\mathrm{P}<0.05)$ in 
LNNA-treated $(n=5)$ animals. Expression of Nrf2, the redoxsensitive transcription factor that counteracts oxidative stress [5] was reduced in L-NNA/high salt-fed $(n=5)$ rats $(29+3 \%$; $\mathrm{P}<0.05)$. DMOG blunted the effect slightly but significantly $(12+2 \% ; \mathrm{P}<0.05)$ [18].

(a)

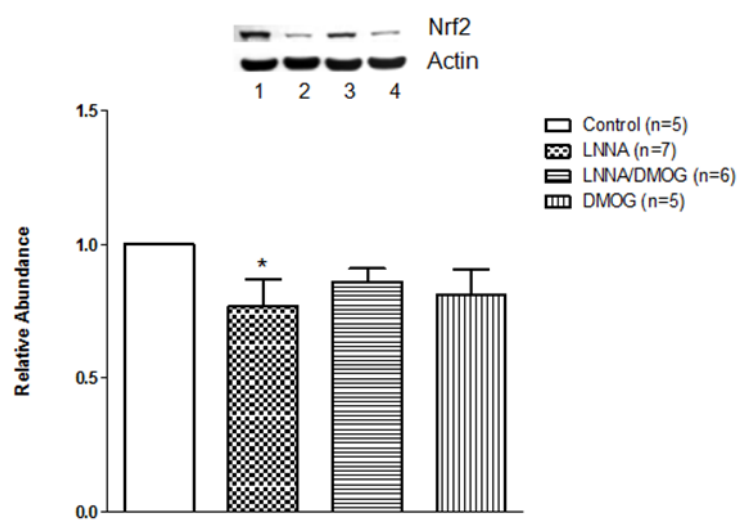

Figure 4a: Expression of Nrf2 in nuclear fractions of whole kidneys of animals treated with high salt diet $(4 \%)$ and L-NNA (250 $\mathrm{mg} / \mathrm{L}$ in drinking water for 14 days) with (LNNA + DMOG, $\mathrm{n}=6$ ) or without DMOG (15 mg/kg i.p. daily; LNNA, $\mathrm{n}=7$ ). Expression of Nrf2 in animals treated with vehicle (Control, $\mathrm{n}=6$ ) or DMOG alone (DMOG, $\mathrm{n}=5$ ) is also shown. Top panel shows representative blots. Lane 1, Control; Lane 2 L-NNA; Lane 3 L-NNA+DMOG; Lane 4 DMOG. Bottom panel shows quantitative analysis.

${ }^{*} \mathrm{P}<0.05$ (L-NNA versus Control)

(b)

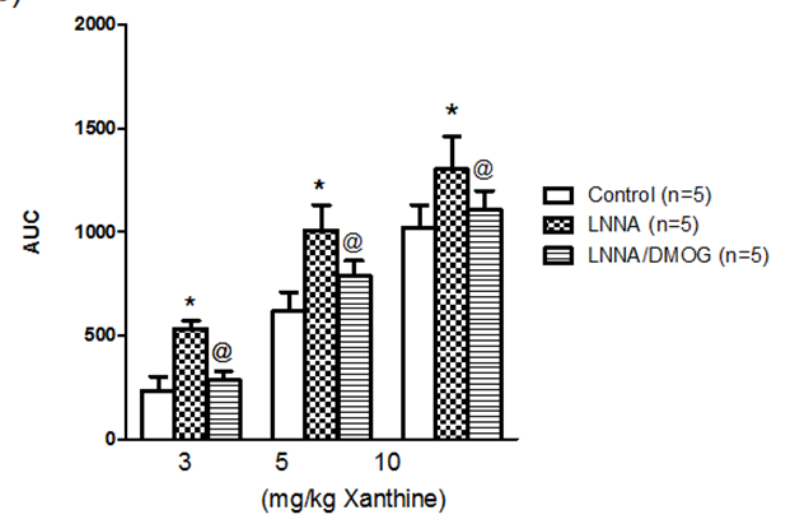

Figure 4b: In vivo generation of $\mathrm{H} 202$ in the kidneys of anesthetized rats in response to xanthine $(3,5$, and $10 \mathrm{mg} /$ $\mathrm{kg}$ bolus i.v.) following treatment with vehicle (Control, $\mathrm{n}=5)$ or high salt diet $(4 \%)$ and L-NNA alone $(250 \mathrm{mg} / \mathrm{L}$ in drinking water for 14 days, $n=5)$ or high salt diet, LNNA and DMOG $(n=5)$. Quantification of the data was done as area under the curve of generation of $\mathrm{H}_{2} \mathrm{O}_{2}$ over 5 minutes.

Effects of inhibition of prolyl hydroxylase domaincontaining protein on NFkB and MYD88 expression in rats following nitric oxide synthase inhibition and high salt diet

Reduced NO bioavailability is associated with activation of $\mathrm{NF \kappa B}$ [2]. Expression of p65, the functional component participating in nuclear translocation and activation of $N F \kappa B$ was elevated $(53+7 \%$; $\mathrm{P}<0.05)$ in animals treated with L-NNA $(250 \mathrm{mg} / \mathrm{L})$ but this was abolished $(\mathrm{P}<0.05)$ in rats treated with DMOG. Since MyD88, an adaptor protein activates NFKB $[19,20]$ and participates in inflammatory responses, we evaluated its expression to determine its correlation to $\mathrm{NF \kappa B}$ expression/ activity following NO withdrawal. In animals $(n=7)$ treated with L-NNA, MyD88 expression increased $(25+4 \%$; $\mathrm{P}<0.05)$ and DMOG abolished its expression such that MyD88 expression was not different between vehicle-treated (Control, $n=5$ ) rats and those treated with L-NNA and DMOG (LNNA/DMOG; n=7) (Figure 5).

(a)

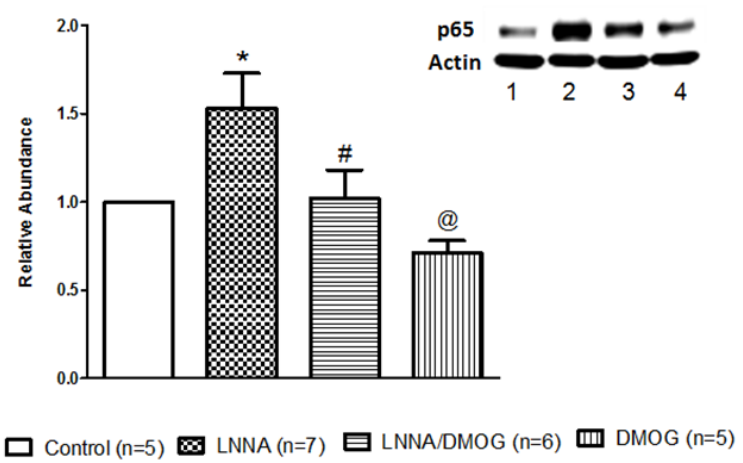

(b)

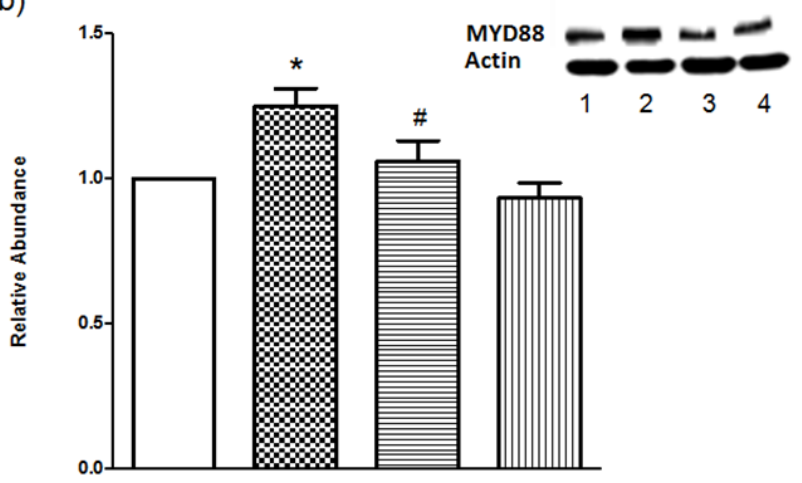

Figure 5: : Expression of p65 (a) or MyD88 (b) in nuclear fractions of whole kidneys of animals treated with high salt diet (4\%) and L-NNA (250 mg/L in drinking water for 14 days) with (LNNA + DMOG, $n=7)$ or without DMOG $(15 \mathrm{mg} / \mathrm{kg}$ i.p. daily; LNNA, $n=6$ ). Expression of p65 or MyD88 in animals treated with vehicle (Control, $n=6$ ) or DMOG alone (DMOG, $n=5$ ) is also shown. Representative blots are shown above the graphs representing quantitative analyses. Lane 1, Control; Lane 2 L-NNA; Lane 3 L-NNA+DMOG; Lane 4 DMOG.

${ }^{*} \mathrm{P}<0.05$ (L-NNA versus Control) \# $\mathrm{P}<0.05$ (L-NNA+DMOG versus L-NNA) @ P $<0.05$ (DMOG versus Control)

Effects of inhibition of prolyl hydroxylase domaincontaining protein on cytokine production in rats following nitric oxide synthase inhibition and high salt diet

Reduced NO availability in association with activation of NFKB [2] is accompanied by gene transcription of proinflammatory cytokines (TNF $\alpha$, IL-1 $\beta)$. Figure 6 illustrates that compared 
to vehicle-treated (control, $n=5$ ) rats, there were several-fold increases in serum production of TNF $\alpha$ and IL-1 $\beta$ in L-NNA/high salt-fed $(n=7)$ rats. These increases were markedly blunted in rats treated with DMOG (LNNA/DMOG). However, DMOG, on its own, did not have an effect on the serum production of TNF $\alpha$ or IL-1 $\beta$.

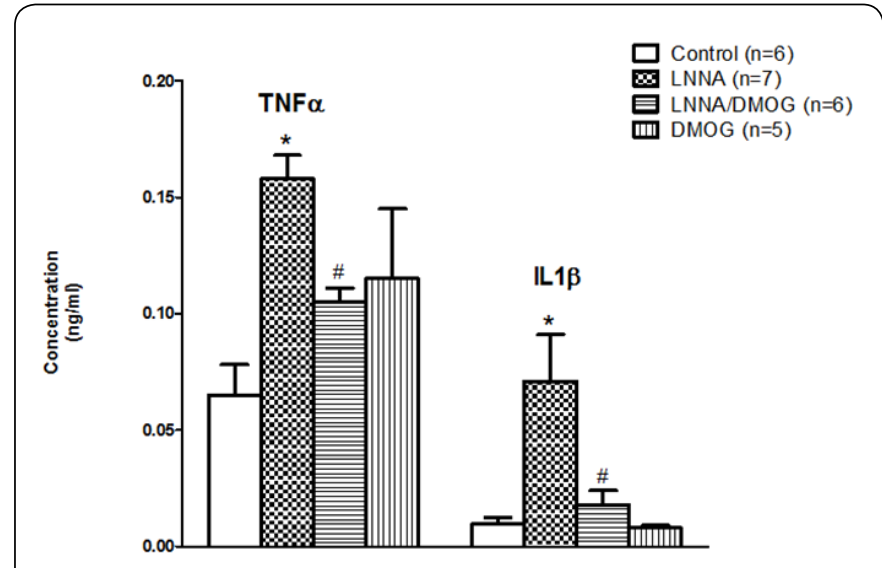

Figure 6: Cytokine (TNF $\alpha$ and IL1 $\beta$ ) production in the blood of rats treated with high salt diet $(4 \%)$ and L-NNA $(250 \mathrm{mg} / \mathrm{L}$ in drinking water for 14 days) with (LNNA + DMOG, $n=7$ ) or without DMOG (15 mg/kg i.p. daily; LNNA, $\mathrm{n}=6)$. Cytokine production in in animals treated with vehicle (Control, $n=6$ ) or DMOG alone (DMOG, $\mathrm{n}=5$ ) is also shown.

${ }^{*} \mathrm{P}<0.05$ (L-NNA versus Control) \# $\mathrm{P}<0.05$ (L-NNA+DMOG versus L-NNA) @ P $<0.05$ (DMOG versus Control)

\section{Effects of DMOG on beclin 1 expression in rats following nitric oxide synthase inhibition and high salt diet}

Autophagy, a cellular defense mechanism that protects the cell from injurious stimuli has been associated with treatment with DMOG [21]. Expression of beclin 1, a biomarker of autophagy, was greater $(28+5 \%, P<0.05)$ in rats $(n=5)$ treated with L-NNA and high salt (LNNA) compared to control $(n=4)$ rats. In addition, DMOG which did not affect basal expression of beclin 1 blunted its expression $(52+4 \%$; $\mathrm{P}<0.05)$ in L-NNA/ high salt-fed rats (LNNA/DMOG). This effect is similar to that produced by chloroquine (data not shown), a known inhibitor of autophagy.

\section{Discussion}

PHD, a putative regulator of cardiovascular function is a target for the therapy of many cardiovascular diseases including but not limited to renal ischemic injury [7], myocardial I/R injury [8], and cerebral ischemia [9]. It has also been reported to interact and/or be involved in the actions and signaling of many mediators such as NO, reactive oxygen species (ROS), and NFKB. The current study evaluated downstream signaling events, namely; PHD, Nrf2, and NFKB following reduced availability of NO and attendant hypertensive renal injury/inflammation.

The effects of NO on PHD are complex and well documented [13] - acute exposure to high doses of NO blocked PHD activity whereas chronic exposure to low doses produced the opposite effect [22]. It, therefore, stands to reason that blockade of low (physiologic) doses of NO as in this study will reverse the stimulant effect of low dose NO on PHD leading to reduced PHD2 expression. This was indeed the case. There is paucity of data on the effects of NOS inhibition on PHD expression and/or activity and vice versa but one study demonstrated that PHD inhibition increased iNOS expression in hypoxia-induced inflammation [23]. Though contrary to our previous observation in the uninephrectomized rat [18], inhibition of NOS in this study was accompanied by a selective down-regulation of PHD2 that was not affected by DMOG, a pan PHD inhibitor, indicating that NO withdrawal caused a maximal down regulation of PHD2.

Renal injury caused by NO withdrawal and/or high salt diet in this study manifested as proteinuria and increased expression of KIM-1, an index of tubular injury that were blunted by DMOG. Hypertension accompanied by renal injury is typical of different models of hypertension [18]. However, in this study, DMOG did not affect L-NNA-induced hypertension indicating that the effect of PHD inhibition on blood pressure is independent of its effect on renal injury. The same goes for the natriuresis elicited by NO withdrawal that was unaffected by DMOG especially on Day 14 of the study. These data appear to suggest "off-target" effects of DMOG that may account for its distinct renoprotection without an accompanying antihypertensive effect. In support of this notion, DMOG has been reported to induce autophagy in a HIFindependent manner [21]. However, this does not seem to be the case considering that DMOG inhibited autophagy (Figure 7).

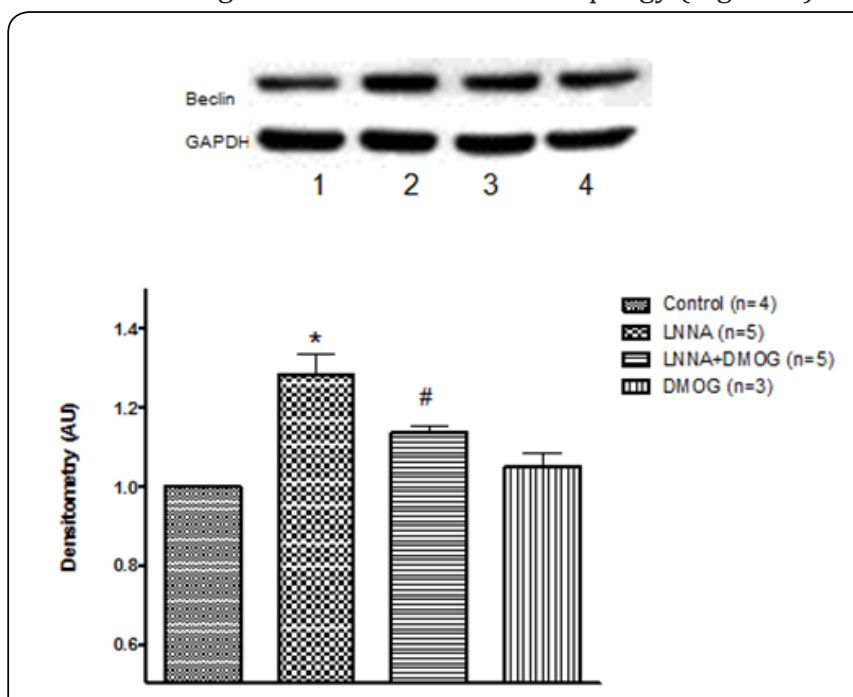

Figure 7: Beclin 1 expression in the whole kidney of animals treated with high salt diet (4\%) and L-NNA (250 mg/L in drinking water for 14 days) with (LNNA + DMOG, $n=5)$ or without DMOG (15 mg/kg i.p. daily; LNNA, $\mathrm{n}=5$ ). Expression of p65 or MyD88 in animals treated with vehicle (Control, $n=4)$ or DMOG alone (DMOG, n=3) is also shown. Representative blots are shown above the graphs representing quantitative analyses. Lane 1, Control; Lane 2 L-NNA; Lane 3 L-NNA+DMOG; Lane 4 DMOG.

${ }^{*} \mathrm{P}<0.05$ (L-NNA versus Control)

\# $\mathrm{P}<0.05$ (L-NNA+DMOG versus L-NNA) 
NO withdrawal or high salt has also been reported to stimulate oxidative stress $[16,17]$ that has been linked to Nrf2. $\mathrm{Nrf2}$ is a major player in the coordinated induction of genes encoding numerous antioxidant and phase II detoxifying enzymes and related proteins [4]. The regulation of cellular antioxidant/anti-inflammatory process is a known defense mechanism against oxidative stress [5], a critical component in the progression of kidney disease $[24,25]$. The exacerbation of inflammatory oxidative stress and renal injury that was accompanied by diminution of several antioxidant genes following deletion of Nrf2 gene [26] supports this notion. Consistent with these observations, our data showed that L-NNA evoked an increase in xanthine-induced generation of $\mathrm{H} 2 \mathrm{O} 2$ that was accompanied by down-regulation of Nrf2. Reactive oxygen species, especially hydroperoxides are potent activators of the redox-sensitive $\mathrm{NF \kappa B}$, a key transcription factor and master regulator of many proinflammatory and profibrotic cytokines and other mediators was increased in renal failure [14]. Since there was a concomitant increase in p65 expression, an index of $\mathrm{NF} \kappa \mathrm{B}$ activation, the reduced Nrf2 expression in these studies is probably linked to $\mathrm{NF} \kappa \mathrm{B}$ activation. Moreover, the increase in serum production of TNF $\alpha$ and IL- $1 \beta$ appears to suggest that renal injury and attendant inflammation induced by L-NNA is linked to $\mathrm{NF}_{\kappa} \mathrm{B}$ activation and attendant inflammation. The reported anti-inflammatory function of $\mathrm{Nrf2}[4,27,28]$ supports this notion.

The possible involvement of other signaling mediators in L-NNA-treated rats came from the increased expression of myeloid differentiation primary response gene 88 (MyD88). MyD88 is an adaptor protein which activation is linked downstream to the activation of kinases that degrade $\mathrm{I} \kappa \mathrm{B}$, which frees NFKB to translocate to the nucleus where it binds $\kappa B$ sites in the promoter region of genes encoding pro-inflammatory cytokines, including IL1B and IL6 [20,29]. The attendant increase in MyD88 expression in L-NNA-treated, high salt-fed rats that was coincident with increased p65 expression, increased $\mathrm{H} 2 \mathrm{O} 2$ production, and increased cytokine production in this study suggests a correlation between NFKB activation and Nrf2 in this model of renal injury [29].

PHD proteins have been reported to hydroxylate many cardiovascular targets such as IKK $\beta$ [30] for subsequent ubiquitin-mediated degradation. Indeed, IKK $\beta$ contains, within its activation loop, an evolutionarily conserved consensus motif for hydroxylation by PHDs. However, the role of PHD in inflammation is still controversial. Thus, while siRNA against PHD-1 or PHD-2 or DMOG resulted in NFKB activation, over expression of PHD induced a decrease in cytokine-stimulated $\mathrm{NF} \kappa \mathrm{B}$ reporter activity [30]. Other studies contradicted these observations as deletion of PHD2 inhibited NFKB expression $[10,31]$. Our data showing reduced PHD2 expression coincident with increased expression of p65 and MyD88 in L-NNA-treated animals link MyD88 to NFKB but does not indicate a critical role for PHD in as much as there was no further inhibition of PHD by DMOG in LNNA-treated animals despite these changes.

The down-regulation of Nrf2 by L-NNA coupled with the lack of additional reduction in PHD2 expression by DMOG suggests non PHD effects of DMOG. DMOG induction of autophagy in a HIF-independent manner has been reported [21]. Autophagy is a dynamic and protective process present in all cells at low levels under basal conditions but can be up regulated by stimuli such as nutrient starvation or hypoxia. However, in this study, autophagy was induced following NO withdrawal as seen by increased expression of beclin 1 , an index of autophagy. DMOG blunted not induce autophagy [22-31].

\section{Conclusion}

In conclusion, data from these studies suggest that the absence of nitric oxide plus high salt diet caused a down regulation of expression of PHD2 and Nrf2 but increased expression of NFKB and MyD88, its downstream target. While these genes probably account for the hypertensive renal injury, the protective effects produced by DMOG may also occur through non PHD-dependent mechanisms but not through autophagy.

\section{Acknowledgment}

Research reported in this publication was supported by the National Institute on Minority Health and Health Disparities of the National Institute of Health under Award Number G12MD007605. The content is solely the responsibility of the authors and does not necessarily represent the official views of the National Institute of Health

\section{References}

1. Iwata NG, Pham M, Rizzo NO, Cheng AM, Maloney E, et al. (2011) Trans fatty acids induce vascular inflammation and reduce vascular nitric oxide production in endothelial cells. PLoS One 6(12): e29600.

2. Rizzo NO, Maloney E, Pham M, Luttrell I, Wessells H, et al. (2010) Reduced NO-cGMP signaling contributes to vascular inflammation and insulin resistance induced by high-fat feeding. Arterioscler Thromb Vasc Biol 30(4): 758-65.

3. Maraslioglu M, Oppermann E, Blattner C, Weber R, Henrich D, et al. (2014) Chronic Ethanol Feeding Modulates Inflammatory Mediators, Activation of Nuclear Factor- $\mathrm{B}$, and Responsiveness to Endotoxin in Murine Kupffer Cells and Circulating Leukocytes. Mediators of Inflammation 2014: 16.

4. Li W, Khor TO, Xu C, Shen G, JWS, et al. (2008) Activation of Nrf2antioxidant signaling attenuates NF-kB-inflammatory response and elicits apoptosis. Biochem Pharmacol 76(1): 1485-1489.

5. Venugopal R, Jaiswal AK (1996) Nrf1 and Nrf2 positively and c-Fos and Fra1 negatively regulate the human antioxidant response elementmediated expression of NAD(P)H:quinone oxidoreductase1 gene. Proc Natl Acad Sci U S A 93(25): 14960-14965.

6. Kim HJ, Vaziri ND (2010) Contribution of impaired Nrf2-Keap1 pathway to oxidative stress and inflammation in chronic renal failure. Am J Physiol Renal Physiol 298(3): F662-671.

7. Matsuura H, Ichiki T, Ikeda J, Takeda K, Miyazaki R, et al. (2011) Inhibition of prolyl hydroxylase domain-containing protein 
downregulates vascular angiotensin II type 1 receptor. Hypertension 58(3): 386-393.

8. Xi L, Taher M, Yin C, Salloum F, Kukreja RC (2004) Cobalt chloride induces delayed cardiac preconditioning in mice through selective activation of HIF-1a and AP-1 and iNOS signaling. Am J Physiol Heart Circ Physiol 287(6): H2369-H2375.

9. Bergeron M, Gidday JM, Yu AY, Semenza GL, Ferriero DM, et al. (2000) Role of hypoxia-inducible factor-1 in hypoxia-induced ischemic tolerance in neonatal rat brain. Ann Neurol 48(3): 285-296.

10. Takeda K, Ichiki T, Narabayashi E, Inanaga K, Miyazaki R, et al. (2009) Inhibition of prolyl hydroxylase domain-containing protein suppressed lipopolysaccharide-induced TNF-alpha expression. Arterioscler Thromb Vasc Biol 29(12): 2132-2137.

11. Callapina M, Zhou J, Schmid T, Kohl R, Brune B (2005) NO restores HIF1 a hydroxylation during hypoxia: role of reactive oxygen species. Free Radic Biol Med 39(70): 925-936.

12. Brune B, Zhou J (2007) Nitric oxide and superoxide. Cardiovasc Res 75: $275-282$.

13. Berchner-Pfannschmidt U, Tug S, Kirsch M, Fandrey J (2010) Oxygensensing under the influence of nitric oxide. Cell Signal 22(3): 349-356.

14. Fujihara CK, Antunes GR, Mattar AL, Malheiros DM, Vieira JM Jr, et al. (2007) Chronic inhibition of nuclear factor- $\mathrm{kB}$ attenuates renal injury in the 5/6 renal ablation model. Am J Physiol Renal Physiol 292(1): F92-99.

15. Vaziri ND, Bai Y, Ni Z, Quiroz Y, Rodriguez Iturbe B (2007) Intrarenal angiotensin II/AT 1 receptor, oxidative stress, inflammation and progressive injury in renal mass reduction. J Pharmacol Exp Ther 323(1): 85-93.

16. Taylor NE, Glocka P, Liang M, Cowley AW (2006) NADPH oxidase in the renal medulla causes oxidative stress and contributes to salt-sensitive hypertension in Dahl S rats. Hypertension 47(4): 692-698.

17. Majid DSA, Nishiyama A, Jackson KE, Castillo A (2004) Inhibition of nitric oxide synthase enhances superoxide activity in canine kidney. Am J Physiol Regul Integr Comp Physiol 287(1): R27-R32.

18. Dallatu MK, Choi M, Oyekan AO (2013) Inhibition of prolyl hydroxylase domain-containing protein on hypertension/renal injury induced by high salt diet and nitric oxide withdrawal. J Hypertens 31(10): 20432049.

19. Robinson D, K Shibuya, A Mui, F Zonin, E Murphy, et al. (1997) IGIF does not drive Th1 development but synergizes with IL-12 for interferon- $\gamma$ production and activates IRAK and NFKB. Immunity 7(4): 571-581.

20. Adachi O, Kawai T, Takeda K, Matsumoto M, Tsutsui H, et al. (1998) Targeted disruption of the MyD88 gene results in loss of IL-1- and IL18-mediated function. Immunity 9(1):1 43-50.

21. Dura'n RV, MacKenzie ED, Boulahbel H, Frezza C, L Heiserich L, et al. (2013) HIF-independent role of prolyl hydroxylases in the cellular response to amino acids. Oncogene 32 (38): 4549-4556.

22. Sandau KB, Fandrey J, Brune B (2001) Accumulation of HIF-1a under the influence of nitric oxide. Blood 97(4): 1009-1005.

23. Egger ME, Huang JS, Yin W, McMasters KM, McNally LR (2013) Inhibition of autophagy with chloroquine is effective in melanoma. J Surg Res 184(1): 274-281.

24. Manning RD, Tian N, Meng S (2005) Oxidative stress and antioxidant treatment in hypertension and the associated renal damage. Am J Nephrol 25(4): 311-317.

25. Remuzzi G, Benigni A, Remuzzi A (2006) Mechanism of progression and regression of renal lesions of chronic nephropathies and diabetes. J Clin Invest 116(2): 228-296.

26. Yoh K, Hirayama A, Ishizaki K, Yamada A, Takeuchi M, et al. (2008) Hyperglycemia induces oxidative and nitrosative stress and increases renal functional impairment in Nrf2-deficient mice. Genes Cells. 13(11): 1159-1170.

27. Chen XL, Dodd G, Thomas S, Zhang X, Wasserman MA, et al. (2006) Activation of Nrf2/ARE pathway protects endothelial cells from oxidant injury and inhibits inflammatory gene expression. Am J Physiol Heart Circ Physiol 290(5): H1862-H1870.

28. Morimitsu Y, Nakagawa Y, Hayashi K, Fujii H, Kumagai T, et al. (2002) A sulforaphane analogue that potently activates the Nrf2-dependent detoxification pathway. J Biol Chem 277(2): 3456-3463.

29. Fitzgerald KA, Palsson McDermott EM, Bowie AG, Jefferies CA, Mansell AS, et al. (2001) Mal (MyD88-adapter-like) is required for Toll-like receptor-4 signal transduction. Nature 413(6851): 78-83.

30. Cummins EP, Berra E, Comerford KM, Ginouves A, Fitzgerald KT (2006) Prolyl hydroxylase-1 negatively regulates IkappaB kinase-beta, giving insight into hypoxia-induced NFkappaB activity. Proc Natl Acad Sci U S A. 103(48): 18154-18159.

31. Zeng H, Chen JX (2014) Conditional knockout of prolyl hydroxylase domain protein 2 attenuates high fat-diet-induced cardiac dysfunction in mice. Plos One 9(12): e115974.

\section{Your next submission with Juniper Publishers will reach you the below assets}

- Quality Editorial service

- Swift Peer Review

- Reprints availability

- E-prints Service

- Manuscript Podcast for convenient understanding

- Global attainment for your research

- Manuscript accessibility in different formats

( Pdf, E-pub, Full Text, Audio)

- Unceasing customer service

Track the below URL for one-step submission

https://juniperpublishers.com/online-submission.php 